\title{
The Application of Fuzzy Comprehensive Evaluation to Risk Assessment of Coal Floor Water Irruption
}

\author{
Huan Huang ${ }^{1, a}$ \\ ${ }^{1}$ Xi'an Research Institute, Xi'an city of Shaanxi Province, China \\ ahuanghuan@cctegxian.com
}

\begin{abstract}
Keywords: evaluation index; analytic hierarchy process; fuzzy comprehensive evaluation; risk assessment of coal floor water irruption; Ordovician limestone water

Abstract: The safety of production in mines are significantly affected by Ordovician limestone water disaster from coal floor, it is very important to evaluate and forecast floor water invasion. Analyzing its influence factors and setting as evaluation indexes for risk assessment of floor water irruption. The fuzzy comprehensive evaluation model is based on adopting fuzzy comprehensive evaluation method to process the fuzzy relationship among indexes, using analytic hierarchy process to quantify the qualitative questions and get the weight of influencing factors. Utilizing the model to evaluate the risk of floor water irruption of 6119 coal face in Suancigou mine, the evaluation result provides reference for Ordovician limestone water disaster prevention and ensures the safety of coal mine.
\end{abstract}

\section{Preface}

Recently, lots of coal mines have begun mining the lower coal group, which seriously affects the safe production of coal mine due to the low distance to Ordovician limestone aquifer and its high water pressure. Therefore, the accurate evaluation and prediction of floor water invasion is crucial. Nowadays the water inrush coefficient gets the extensive application in the water inrush evaluation, but the choice of critical water inrush coefficient is still questionable, and it only considered the water pressure and the effective thickness of water resisting layer without considering the uncertainty factors exist, which can not reflect the water inrush mechanism under comprehensive effect of various factors. In fact, it is affected by the aquifer, aquifuge, mining conditions and geological structure, etc. Certain fuzziness exists among these factors. Using fuzzy mathematics to deal with the fuzzy relation among the influence indexes and the analytic hierarchy process $(A H P)$ can make qualitative questions to be quantitative to determine the weight value of influence factors[1]. Thus, fuzzy synthetic evaluation model based on AHP could be used to evaluate the risk of floor water invasion. In this paper, setting Suancigou coal mine as an example to evaluate risk of floor water invasion of 6119 working face, which aiming at providing reference for safety production.

\section{The Fuzzy Comprehensive Evaluation}

The Basic Principle of Fuzzy Comprehensive Evaluation The fuzzy decision becomes a popular research topic in fuzzy mathematics, it's a mathematical theory and method for making a decision in fuzzy environment or fuzzy system. The major goal of fuzzy decision is to order the objects in decision discourse under fuzzy environment or to pick out the optimal objects from decision discourse according to some fuzzy constraints. The fuzzy comprehensive evaluation is one of the important methods[2,3].

The fuzzy comprehensive evaluation is a method to evaluate the level status of membership degree for the object evaluated, which is based on composition of fuzzy relation theory, the concrete steps show as following:

(1) Determining the discourse domain $U$ of influence factors of the evaluated object, $U=\left\{u_{1}, u_{2}, \ldots, u_{\mathrm{n}}\right\}$.

(2) Creating remark collective $V, V=\left\{v_{1}, v_{2}, \ldots, v_{\mathrm{m}}\right\}$.

(3) Evaluating the single factor and establishing fuzzy relation matrix $R$ 


$$
R=\left[\begin{array}{cccc}
r_{11} & r_{12} & \cdots & r_{1 m} \\
r_{21} & r_{22} & \cdots & r_{2 m} \\
\vdots & \vdots & \vdots & \vdots \\
r_{n 1} & r_{n 2} & \cdots & r_{n m}
\end{array}\right] \quad\left(0 \leq r_{i j} \leq 1\right)
$$

Types: $r_{i j}$ is the membership relation of influence factor $u_{i}$ towards evaluation grade $v_{j}$.

(4) Ensuring weight vector of evaluation factors, it depends on the vantage point of fuzzy comprehensive evaluation, that is determining the weight value of each factor according to its significance by AHP.

(5) Choosing fuzzy composite operator.

$$
B=A \circ R=\left(a_{1}, a_{2}, \cdots, a_{\mathrm{n}}\right) \circ\left[\begin{array}{cccc}
r_{11} & r_{12} & \cdots & r_{1 m} \\
r_{21} & r_{22} & \cdots & r_{2 m} \\
\vdots & \vdots & \vdots & \vdots \\
r_{n 1} & r_{n 2} & \cdots & r_{n m}
\end{array}\right]
$$

Types: $\circ$ is the fuzzy composite operator, here time the mean weighted fuzzy composite operator is chose.

(6) Analyzing and processing the comprehensive evaluation result $B$, determining the evaluation grade according to the maximum membership degree law.

Establishing The Fuzzy Relation Matrix.The fuzzy boundary is described by membership degree when applying fuzzy mathematics to fuzzy comprehensive judgment. The composition of fuzzy relation matrix is the membership degree of a single factor $u_{i}$ belongs to which evaluation grade. The membership degree is calculated by membership functions, such as the lower semi-trapezoid distribution function[4], $u_{i}$ is the actual measured value of the $i^{\text {th }}$ evaluating index and $c_{i j}$ is standard value of $j^{\text {th }}$ evaluation grade. The membership functions can be expressed as following:

The membership functions of first evaluation standard, $j=1$.

$$
r_{i 1}=\left\{\begin{array}{cc}
1 & u_{i} \leq c_{i 1} \\
\frac{c_{i 2}-u_{i}}{c_{i 2}-c_{i 1}} & c_{i 1} \leq u_{i} \leq c_{i 2} \\
0 & u_{i} \geq c_{i 2}
\end{array}\right.
$$

The membership functions of $j^{\text {th }}$ evaluation standard, $j=2,3, \ldots, n-1$.

$$
r_{i j}=\left\{\begin{array}{lc}
\frac{u_{i}-c_{i j-1}}{c_{i j}-c_{i j-1}} & c_{i j-1} \leq u_{i} \leq c_{i j} \\
\frac{c_{i j+1}-u_{i}}{c_{i j+1}-c_{i j}} & c_{i j}<u_{i} \leq c_{i j+1} \\
0 & u_{i} \leq c_{i j-1} \text { or } u_{i}>c_{i j+1}
\end{array}\right.
$$

The membership functions of $n^{\text {th }}$ evaluation standard, $j=n$.

$$
r_{i n}=\left\{\begin{array}{cc}
0 & u_{i} \leq c_{i n-1} \\
\frac{u_{i}-c_{i n-1}}{c_{i n}-c_{i n-1}} & c_{i n-1}<u_{i}<c_{i n} \\
1 & u_{i} \geq c_{i n}
\end{array}\right.
$$

The Weight Value of Index.The analytic hierarchy process, which is a multi-criteria decision method to make quantitative analysis of qualitative questions, is put forward by operations researcher of USA T.L.Saaty in 1970s. This method can be reduced to six steps such as define the problem, establish hierarchy, build judgment matrix, hierarchy single ranking and its uniformity test, hierarchy general ranking and its uniformity test. Selecting evaluating indexes, and ordering the evaluation indexes 
according to AHP grading standard. The judgment matrix is constructed with paired comparison method and 1 9 scale law, and calculate the maximum eigenvalue $\lambda$ max and its corresponding eigenvector $A_{i}$ of judgment matrix. The uniformity test is conducted by the following function:

$$
C I=\frac{\lambda_{\max }-n}{n-1}
$$

Types: $C I$ is consistency index, $R I$ is random-index, $C R$ is coincidence coefficient and $n$ is judgment matrix order.

When $C R<0.1$, it satisfies the uniformity test, and the normalization eigenvector is weight vector.

When $C R \geq 0.1$, the judgment matrix should be rewritten.

\section{Example Analysis}

The General Situation of Research Area.Suancigou coal mine lies in the Midwest of Zhungeer coal field, the terrain is higher in north lower in south generally, and higher in middle lower in east-west direction. The formation from old to new is Liangjiashan formation of lower Ordovician $\left(O_{11}\right)$, Majiagou formation of middle Ordovician $\left(O_{2 m}\right)$, Benxi formation of middle Carboniferous $\left(C_{2 b}\right)$, Taiyuan formation of upper Carboniferous $\left(C_{2 t}\right)$, Shanxi formation of lower Permian $\left(P_{1 s}\right)$, lower shihezi formation of lower Permian $\left(P_{2 s}\right)$, upper shihezi formation of upper Permian $\left(P_{2 s}\right)$, Shiqianfeng formation of upper Permian $\left(P_{2 s h}\right)$, the red soil layer of Tertiary $\left(N_{2}\right)$, the Quaternary $(Q)$. Among them the Taiyuan formation and Shanxi formation is the coal-bearing strata, seam 6\# is the main coal mining at present, the coal thickness arrange from $5 \mathrm{~m}$ to $13.5 \mathrm{~m}$, the distance from coal floor to Ordovician limestone aquifer arrange from $54.55 \mathrm{~m}$ to $80.25 \mathrm{~m}$, the pressure of Ordovician limestone water arrange from 0 to $3.2 \mathrm{MPa}$.

6119 working face is located in south of coal field, the average coal thickness is $5.5 \mathrm{~m}$ and the burial depth arrange from $450 \sim 483 m$, so it is under the artesian area. Some parameters can be got from borehole data, such as the average pressure of Ordovician limestone water is $2.1 \mathrm{MPa}$, the permeability coefficient is $0.165 \mathrm{~m} / \mathrm{d}$, the effective thickness of aquifuge is $42 \mathrm{~m}$, the integrity index of aquifuge is 0.459. Fault density is 0.345 which could be calculated by faults exposed in working face. The characteristic of floor aquifuge is sandstone interbedded mudstone, the lithology lies between medium-hard to hard. The floor aquifuge has lower strength and poor integrity due to its erosion zones and tectonic crushed zone partially, and there're several faults $(>5 \mathrm{~m})$ in working face according to 3-D seismic. So, it's necessary to evaluate the risk of floor water invasion for 6119 working face.

The Evaluation Indexes and Evaluation Standard.There are many factors affect the floor water invasion, in this paper considers four aspects such as the aquifer, aquifuge, mining conditions and geological structure, and chooses 10 influence factors as evaluation indexes such as pressure of Ordovician limestone water, units-inflow, permeability coefficient, effective thickness of aquifuge, and so on[5,6,7]. Based on comprehensive consideration of water disaster characteristic and hydrogeological condition in Suancigou coal mine, the risk of floor water invasion is divided into four grades according to national standard, occupational standard, predecessor's research data and relevant experience, that is dangerous, comparative dangerous, comparative safe, safe. The evaluation indexes and the standard of each grade can be seen in Tab. 1.

Tab. 1 The evaluation criteria of risk assessment of coal floor water irruption

\begin{tabular}{|c|c|c|c|c|c|}
\hline Rule hierarchy $B$ & Index hierarchy $C$ & Dangerous & $\begin{array}{c}\text { Comparative } \\
\text { dangerous }\end{array}$ & $\begin{array}{c}\text { Comparative } \\
\text { safe }\end{array}$ & Safe \\
\hline \multirow{3}{*}{ Aquifer } & $\begin{array}{l}\text { Pressure of Ordovician } \\
\text { limestone water } C_{1}(M p a)\end{array}$ & 4 & 3 & 2 & 1 \\
\hline & Units-inflow $C_{2} L /\left(s^{*} m\right)$ & 5 & 2 & 0.1 & 0.05 \\
\hline & $\begin{array}{l}\text { Permeability coefficient } \\
\qquad C_{3}(\mathrm{~m} / \mathrm{d})\end{array}$ & 1 & 0.7 & 0.05 & 0.01 \\
\hline \multirow{3}{*}{ Aquifuge } & $\begin{array}{l}\text { Effective thickness of } \\
\text { aquifuge } C_{4}(\mathrm{~m})\end{array}$ & 20 & 38 & 50 & 60 \\
\hline & $\begin{array}{l}\text { Ratio of brittle thickness } \\
\text { to plastic thickness } C_{5}\end{array}$ & 1.7 & 1.3 & 0.9 & 0.5 \\
\hline & Integrity index of & 0.1 & 0.4 & 0.6 & 0.8 \\
\hline
\end{tabular}




\begin{tabular}{|c|c|c|c|c|c|}
\hline & $\begin{array}{l}\text { Compressive strength } \\
\qquad C_{7}(\mathrm{MPa})\end{array}$ & 10 & 15 & 20 & 40 \\
\hline \multirow[t]{2}{*}{ Mining conditions } & $\begin{array}{l}\text { Mining thickness } \\
\qquad C_{8}(m)\end{array}$ & 8 & 6 & 3 & 2 \\
\hline & Mining depth $C_{9}(m)$ & 700 & 500 & 400 & 300 \\
\hline Geological structure & Fault density $C_{10}$ & 0.8 & 0.5 & 0.3 & 0.1 \\
\hline
\end{tabular}

The Determination of Index Weight.Setting the risk of floor water invasion as research target of highest level, which should be considered as target layer $A$ according to AHP theory. The aquifer, aquifuge, mining conditions and geological structure determine the risk of floor water invasion, which should be set as rule hierarchy $B$. The rule hierarchy $B$ is a intermediate link, it has its own concrete influence factors, such as pressure of Ordovician limestone water, permeability coefficient, these are used as index hierarchy $C$. Establishing judgment matrix by compare every two factors among various levels with expert estimation. According to $A H P$ theory to define single ordering weight value of rule hierarchy $B$ towards target layer $A$ and index hierarchy $C$ towards rule hierarchy $B$, finally calculates the general ordering weight value of index hierarchy $C$ towards target layer $A$, and the whole process should meet uniformity test[8,9,10]

\begin{tabular}{cccccc}
\multicolumn{6}{c}{ Tab.2 AHP judgment matrix } \\
\hline$A$ & $B_{1}$ & $B_{2}$ & $B_{3}$ & $B_{4}$ & weight \\
\hline$B_{1}$ & 1 & 2 & 3 & 2 & 0.4100 \\
$B_{2}$ & $1 / 2$ & 1 & 2 & 2 & 0.2693 \\
$B_{3}$ & $1 / 3$ & $1 / 2$ & 1 & $1 / 3$ & 0.1088 \\
$B_{4}$ & $1 / 2$ & $1 / 2$ & 3 & 1 & 0.2119 \\
\hline \multicolumn{5}{c}{ notes: $\quad C I_{1}=0.0477$} & $C R_{1}=0.053<0.1$
\end{tabular}

Tab.3 AHP judgment matrix

\begin{tabular}{lcccc}
\hline$B_{1}$ & $C_{1}$ & $C_{2}$ & $C_{3}$ & weight \\
\hline$C_{1}$ & 1 & 2 & 3 & 0.5278 \\
$C_{2}$ & $1 / 2$ & 1 & 3 & 0.3325 \\
$C_{3}$ & $1 / 3$ & $1 / 3$ & 1 & 0.1396 \\
\hline notes: & $C_{21}=0.0268$ & \multicolumn{2}{c}{$C_{21}=0.051<0.1$}
\end{tabular}

Tab.4 AHP judgment matrix

\begin{tabular}{cccccc}
\hline$B_{2}$ & $C_{4}$ & $C_{5}$ & $C_{6}$ & $C_{7}$ & weight \\
\hline$C_{4}$ & 1 & 3 & 2 & 2 & 0.4455 \\
$C_{5}$ & $1 / 3$ & 1 & $1 / 2$ & 1 & 0.1536 \\
$C_{6}$ & $1 / 2$ & $1 / 2$ & 1 & 2 & 0.2278 \\
$C_{7}$ & $1 / 2$ & 1 & $1 / 2$ & 1 & 0.1730 \\
\hline \multicolumn{3}{c}{ notes: $\quad C I_{22}=-0.055$} & \multicolumn{3}{c}{$C R_{22}=-0.062<0.1$}
\end{tabular}

\begin{tabular}{cccc}
\multicolumn{4}{c}{ Tab.5 AHP judgment matrix } \\
\hline$B_{3}$ & $C_{8}$ & $C_{9}$ & weight \\
\hline$C_{8}$ & 1 & $1 / 2$ & 0.3333 \\
$C_{9}$ & 2 & 1 & 0.6667 \\
\hline & notes: & $C_{23}=0$ & \multicolumn{3}{c}{$C R_{23}=0<0.1$}
\end{tabular}

It can be concluded that all judgment matrix satisfy uniformity test from Tab. 2 to Tab. 5. Now the general ordering weight value could be calculated by single ordering weight value. We can get the general ordering coincidence coefficient by following function. It satisfies uniformity test when $C R_{2}<0.1$.

$$
C R_{2}=C R_{1}+\frac{C I_{2}}{R I_{2}}=C R_{1}+\frac{\sum_{1}^{3} C I_{2 i} W_{A / B_{i}}}{\sum_{1}^{3} R I_{2 i} W_{A / B_{i}}}
$$

The result $C R_{2}=0.044$ shows that general ordering weight value meets uniformity test and the analytic hierarchy model established meets the requirement. Finally gets the general ordering weight value of concrete influence factors toward the floor water invasion. 
Tab.6 General ranking weight

\begin{tabular}{cccccc}
\hline influence index & $C_{1}$ & $\mathrm{C}_{2}$ & $\mathrm{C}_{3}$ & $\mathrm{C}_{4}$ & $\mathrm{C}_{5}$ \\
weight $\boldsymbol{A}$ & 0.2164 & 0.1363 & 0.0573 & 0.12 & 0.0414 \\
influence index & $\mathrm{C}_{6}$ & $\mathrm{C}_{7}$ & $\mathrm{C}_{8}$ & $\mathrm{C}_{9}$ & $\mathrm{C}_{10}$ \\
weight $\boldsymbol{A}$ & 0.0613 & 0.0466 & 0.0363 & 0.0725 & 0.2119 \\
\hline
\end{tabular}

The Fuzzy Comprehensive Evaluation of Risk of Floor Water Invasion.The influence indexes value are comprehensively determined according to borehole data in 6119 working face and evaluation standard fuzzy matrix $R$ could be created by calculating the membership degree of evaluation indexes toward evaluation grade.

$$
R=\left[\begin{array}{cccc}
0 & 0.1 & 0.9 & 0 \\
0.0333 & 0.9667 & 0 & 0 \\
0 & 0.1769 & 0.8231 & 0 \\
0 & 0.6667 & 0.3333 & 0 \\
0 & 0.535 & 0.465 & 0 \\
0 & 0.701 & 0.299 & 0 \\
0 & 0 & 0.36 & 0.64 \\
0 & 0.8333 & 0.1667 & 0 \\
0 & 0.325 & 0.675 & 0 \\
0.275 & 0.725 & 0 & 0
\end{array}\right]
$$

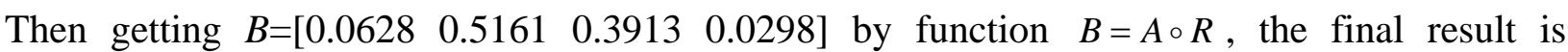
$B=0.5161$ by the greatest principle the subject degree and the evaluation grade is II. Thus, the 6119 working face belongs to comparative dangerous area and the prevention measures should be taken for safety during coal mining.

\section{Conclusions}

(1) The application of analytic hierarchy process to evaluate the risk of floor water invasion could be quantitative the influence degree of evaluation indexes toward floor water invasion and gets the weight value of each influence factors. It is practical for its clear in concept and simple in calculating.

(2) Using the fuzzy comprehensive evaluation method based on analytic hierarchy process to evaluate the risk of floor water invasion. It not only considers the fuzziness of evaluation indexes, but also reflects the influence degree of each evaluation indexes toward to floor water invasion when using the fuzzy comprehensive evaluation. The result shows that the Ordovician limestone water threats the safety mining of 6119 working face and it provides reference for safety production in future.

\section{References}

[1] SAATY T L. The analytic hierarchy process[M]. New York: McGraw-Hill, 1980.

[2] YANG Lun-biao, GAO Ying-yi. Fuzzy mathematics principle and its application[M]. South China University of Technology Press, 2011.

[3] XIE Ji-jian, LIU Cheng-ping. Fuzzy mathematics method and its application[M]. Wuhan: Huadong University of Science \& Technology Press, 2013.

[4] JI Ya-dong. Evaluation of groundwater quality in Yinchuan area by using fuzzy comprehensive evaluation method[J]. Geology of Shaanxi, 2004,22(1).

[5] Water-richness evaluation method of water-filled aquifer based on the principle of information fusion with GIS:Water-richness index method[J]. Journal of China Coal Society, 
2011,36(7):1124-1128.

[6] WU Qiang, ZHANG Zhi-long, MA Ji-fu. A new practical methodology of the coal floor water bursting evaluating I - The master controlling index system construction[J]. Journal of China Coal Society, 2007,32(1):42-47.

[7] WU Qiang, LIU Shou-qiang, JIA Guo-kai. Application of vulnerable index method in the assessment of water outbursts from coal seam floor[J]. China Coal, 2010,36(6):15-17.

[8] LI Bo, GUO Jun, LI Heng-kai, et al. Comprehensive assessment on coal roof water bursting risk in Karst area based on fuzzy comprehensive evaluation[J]. Chinese Coal, 2012,38(8):51-54 .

[9] WANG Shuang-ying, WU Chao, ZUO Hong-yan. Fuzzy analytic hierarchy process assessment model of safety production for small and medium coal mines and its application[J]. Journal of Central South University(Science and Technology), 2010,41(5):1918-1922.

[10] Mikhailov L, Tsvetinov P.Evaluation of services using a fuzzy analytic hierarchy process[J]. Applied Soft Computing,2004,5(1):23-33. 